\title{
A Simple DC-UPS Based in Forward-Forward Topology, Design and Simulation
}

\author{
Flores L. A., García O. ${ }^{*}$, Román A. and Esparza-González M. S. ${ }^{* *}$ \\ Departamento de Sistemas Electrónicos, Universidad Autónoma de Aguascalientes, México, lflores@correo.uaa.mx \\ *Centro de Electrónica Industrial (CEI), Universidad Politécnica de Madrid, ETSII, España, o.garcia@upm.es \\ **Departamento de Ingeniería Eléctrica, Instituto Tecnológico de Aguascalientes, México, msespa@ieee.org
}

\begin{abstract}
This paper presents the analysis, design and simulation of a simple DC-UPS converter with integrated back-up and automatic transition. This converter makes automatic transitions between the main $A C$ and the battery when a failure occurs; and it delivers uninterrupted $D C$ power to the load through two independent power sources of commercial input power and battery power. The converter has the following characteristics: automatic transition between the main and the battery, no additional control to detect failure in main, single structure, galvanic isolation, multi output voltages capability and only one switch control for two operation modes: normal and back-up. The analysis, design and simulation for this converter are presented.
\end{abstract}

\section{Introduction}

Typical UPSes provide an ac output voltage and are made with a structure integrated by an ac rectifier a battery charger and an inverter, and several of these structures can be classifies as in-line, line interactive, or off-line [1]-[2]. In this kind of UPSes an inverter changes the dc voltage in to ac voltage to feed "critical loads". However, the loads that are fed by this UPSes normally are integrated too with an ac rectifier and one or two DC-DC converters in order to obtain the different output voltages needed to feed the final loads. This fact, cause that the energy process must be realized five or six times, causing a very low efficiency in all the transformation process. In order to avoid unnecessary energy processes with the typical UPSes and critical loads, the use of DC-UPSes has been increased in the last decades in the equipment of telecommunications and portable electronic equipment [3]-[11]. As a consequence this results in improvements as well as in the structure to reduce size, weight efficiency and cost. Although several approaches to solve the problems started above have been made [4]-[14], only a few of them take into

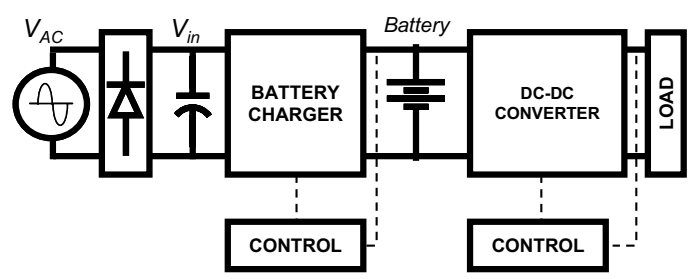

Figure 1. Simple DC-UPS

account the automatic transition in their structure [12][15].

By eliminating the inverter and one rectifier stage, a simple arrangement to deliver DC-UPS is integrated in two stages: first include a battery charger and second a DC-DC converter to regulate output voltage necessary for the load (Figure 1). In this paper we introduce, a description about a family of converters for integrates DC-UPSes. In order to show the operation principle and particular guidelines to simulate and construct these converters, one topology from this family is selected and designed.

\section{Topology description}

Figure 2 shows the general structure of the topology of the DC-UPS converter presented in this paper. This structure is known as CIBAT (Converters with Integrated Back-up and Automatic Transition) and is presented in [15]. CIBAT is a family of four converters where each one consist of a main output a battery charger, one transformer with four windings, one switch $\mathrm{SW}$, two special diodes $\left(\mathrm{D}_{\mathrm{N}}\right.$ and $\mathrm{D}_{\mathrm{B}}$ that make the automatic transition) and two entrances, principal entrance $V_{\text {in }}$ (from main $\mathrm{AC}$ and full bridge diode with capacitor) and battery. Both entrances are connected in the primary winding of the transformer but the battery does it through a centered derivation with $\mathrm{D}_{\mathrm{B}}$. Therefore both entrances share the same transformer, switch, and control loop, resulting in a simple parallel circuit with only one stage. 


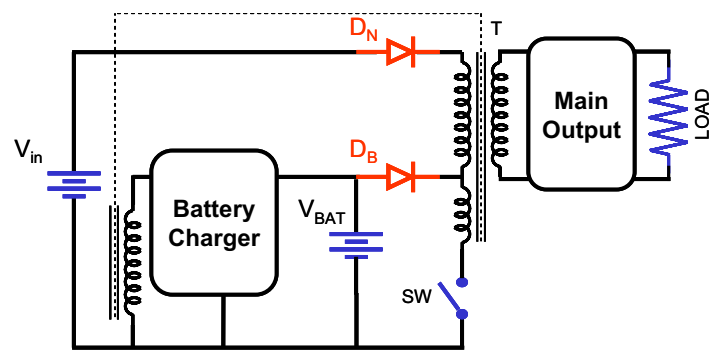

Figure 2. General structure of converter with integrated back-up and automatic transition

CIBAT can adopt different topologies; it depends on the mode to transfer the energy to the load and the mode to charge the battery. The principal structure uses only one converter with two outputs (forward or flyback) to feed the load and charge the battery. Consequently four combinations are made to build the converter: Forward-Forward, Forward-Flyback, Flyback-Forward and Flyback-Flyback, where the first name corresponds to the converter located between the main and the load, and the second name corresponds to one located between the main and the battery. The principal characteristics of this topology are listed below:

Automatic transition: It is possible under the idea if using two diodes to make this transition when a failure occurs and share the same transformer with a centered derivation with $\mathrm{D}_{\mathrm{B}}$. This idea is very important because it is not necessary to use a circuit control detect when a failure occurs, allowing fast dynamic response.

Single structure: These array allow to design a DCUPS with only one stage, achieving thus high efficiency, small size and low cost. The energy is transferred to the output and to the battery simultaneously obtaining high reach.

One switch: This is another important advantage of this kind of converters because all of them use only one switch sharing the primary winding of the transformer, and use only one control loop compensation for both operation modes. This makes the design of the converter very simple, which is an other important characteristic in order to lower costs in industrial applications.

Multi-output voltages: Additional windings can be placed in order to obtain multi- outputs voltages, as shown in Figure 3.

\subsection{Circuit operation}

CIBAT topologies have only two operation modes normal plus battery charger and Back-up mode. Both operation modes are in CCM and share same switch, control loop, and transformer.

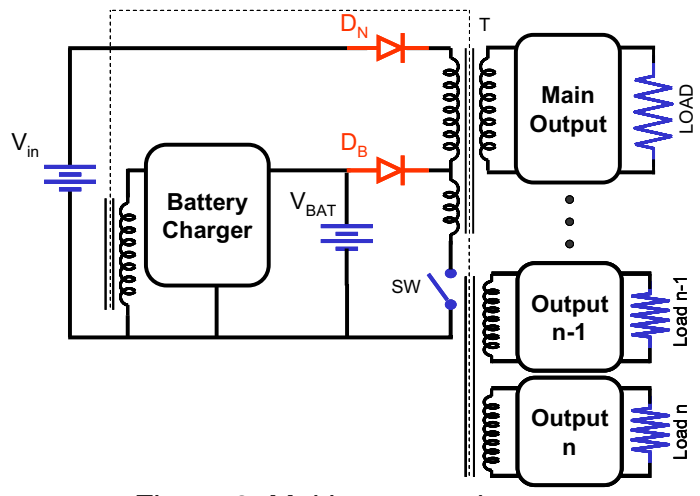

Figure 3. Multi-output voltages.

Normal plus battery charger operation mode. The principle of operation in normal plus battery charger mode in these converters is to transfer energy from $V_{\text {in }}$ to the load and charge the battery simultaneously. In this operation mode $\mathrm{D}_{\mathrm{N}}$ is turned on and $\mathrm{D}_{\mathrm{B}}$ is turned off (Fig.4). In this operation mode $\mathrm{D}_{\mathrm{B}}$ is never in a conduction state guaranteeing thus the correct operation of the converter.

Back-up operation mode. When a failure occurs suddenly in $\mathrm{V}_{\mathrm{AC}}, \mathrm{V}_{\text {in }}$ decrease and $\mathrm{D}_{\mathrm{B}}$ makes an automatic transition to back-up mode due to the fact that the voltage in the anode is higher than in the cathode voltage in $\mathrm{D}_{\mathrm{B}}$, allowing feeding in the load through the battery using the same switch and transformer (Fig.5). When AC main returns, $\mathrm{V}_{\text {in }}$ increases and $D_{B}$ is blocked since the cathode voltage is higher than the battery voltage $\left(\mathrm{V}_{\mathrm{BAT}}\right)$, reaching normal operation mode again.

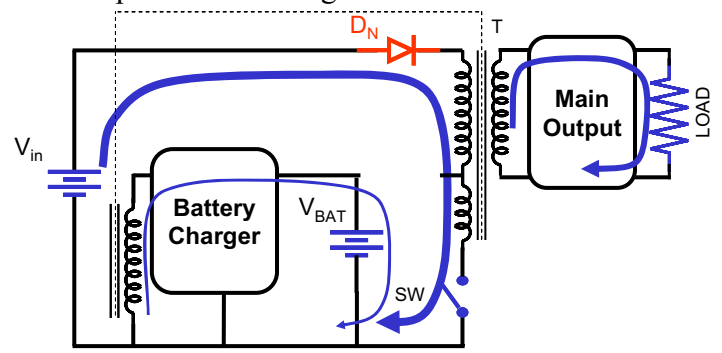

Figure 4. Normal operation mode.

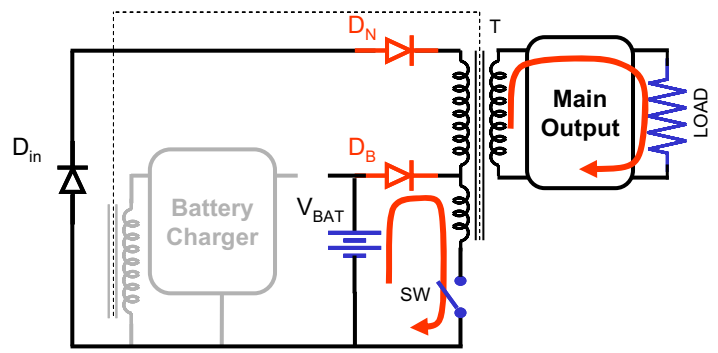

Figure 5. Back-up operation mode. 


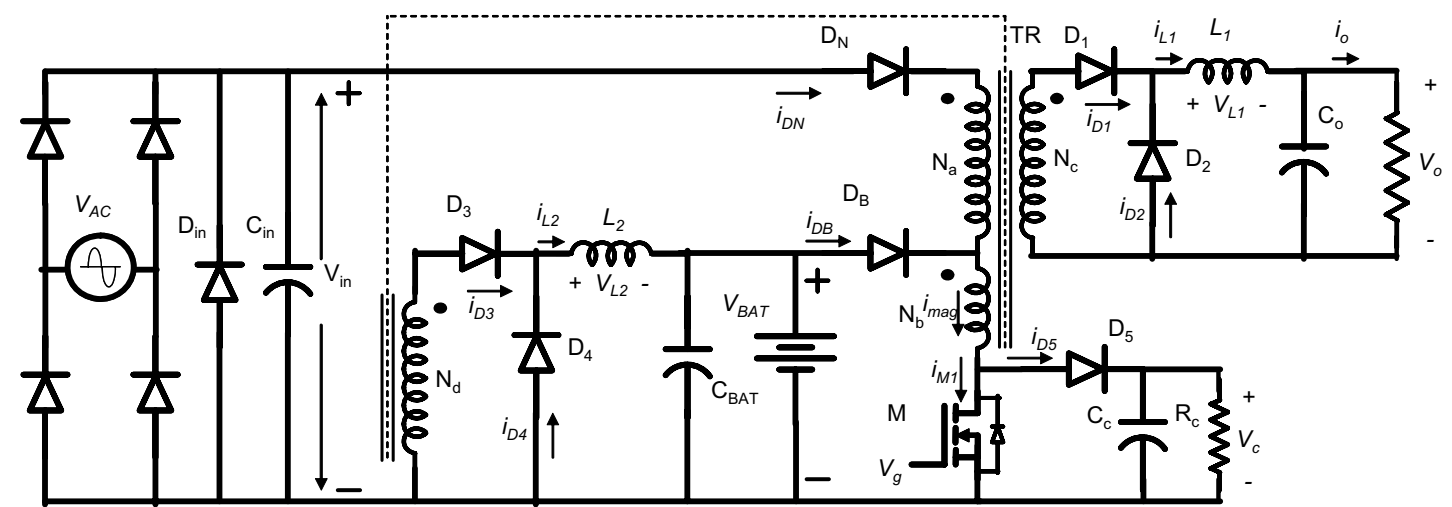

Figure 6. Forward-Forward DC-UPS with RCD network.

\section{Forward-Forward DC-UPS}

As initial analysis from CIBAT family, ForwardForward topology was selected to be designed, simulated and constructed. Figure 6 shows the structure of Forward-Forward DC-UPS, this topology needs an auxiliary system in order to eliminate the magnetizing current $\left(i_{\text {mag }}\right)$. This system is formed by a RCD network $\left(D_{5}, C_{c}\right.$, and $\left.R_{c}\right)$ put in parallel with the switch [16]. The main output is integrated by $D_{1}, D_{2}$, $L_{1}$ and $\mathrm{C}_{\mathrm{o}}$; battery charger is formed by $\mathrm{D}_{3}, \mathrm{D}_{4}, L_{2}$ and $\mathrm{C}_{\text {BAT }}$. Both outputs share the same transformer TR, switch $\mathrm{M}$ and control. The converter is fed by $\mathrm{V}_{\mathrm{BAT}}$ and $\mathrm{V}_{\text {in }}$ that is obtained from the $\mathrm{AC}$ rectifier input and capacitive $C_{i n}$ filter. In order to ensure a good operation of the converter, the RCD network has to eliminate the magnetizing current in both operation modes (Normal plus battery charger and Back-up). Both operation modes are presented.

\subsection{Normal plus battery charger mode}

Equivalent circuit for this operation mode is shown in Fig. 7, where $D_{B}$ is blocked, $V_{A C}$ is considered like a simple DC input voltage $\left(\mathrm{V}_{\text {in }}\right)$ and $\mathrm{N}_{\mathrm{a}}$ consider the total primary winding.

Figure 7. Normal plus battery charger mode

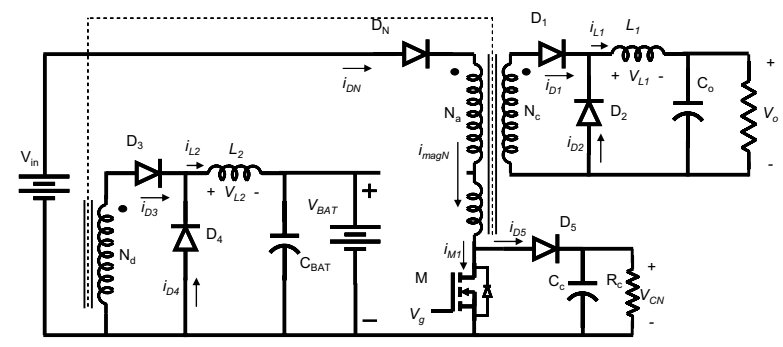

Design this topology resulted very simple, due to is exactly as a simple forward converter with two outputs that share the primary winding of the transformer. Applying balance volts-seconds in $L_{l}$ with continuous conduction mode (CCM) the equation that defines the gain of the converter based on duty cycle $d_{N}$ and turns ration in the transformer TR is:

$$
\mathrm{V}_{\mathrm{o}}=d_{N} \mathrm{~V}_{\text {in }} \frac{\mathrm{N}_{\mathrm{c}}}{\mathrm{N}_{\mathrm{a}}}, \quad 0 \leq d_{N} \leq\left(1-d_{1}\right)
$$

Where $d_{N}=$ duty cycle in normal operation mode, $d_{1}$ $=$ time to eliminate magnetizing current, $V_{\text {in }}=d c$ voltage entrance from rectifiers, $\mathrm{N}_{\mathrm{a}}=$ total primary winding turns and $\mathrm{N}_{\mathrm{c}}=$ output winding turns. In the same form, applying volts-balance in $L_{2}$ with continuous conduction mode (CCM) in order to obtain the equation that defines the voltage $\mathrm{V}_{\mathrm{BAT}}$ in battery charger is:

$$
\mathrm{V}_{\mathrm{BAT}}=d_{N} \mathrm{~V}_{\text {in }} \frac{\mathrm{N}_{\mathrm{d}}}{\mathrm{N}_{\mathrm{a}}}, \quad 0 \leq d \leq\left(1-d_{1}\right)
$$

Average output current in normal mode is:

$$
\hat{i}_{o \mathrm{~N}}=\frac{\mathrm{P}_{\mathrm{o}}}{\mathrm{V}_{\mathrm{o}}}
$$

To calculate the inductance value as function from a ripple current in $L_{l}\left(\Delta i_{N}\right)$ and frequency is:

$$
L_{1}=\frac{\mathrm{V}_{\mathrm{o}}-\mathrm{V}_{\mathrm{o}}^{2} \frac{\mathrm{Na}}{\mathrm{Nc}}}{\Delta i_{\mathrm{N}} \cdot f}
$$

the peak current in the inductor $L_{l}$ is:

$$
i_{\mathrm{pkN}}=\hat{i}_{o \mathrm{~N}}+\frac{\Delta i_{N}}{2}
$$




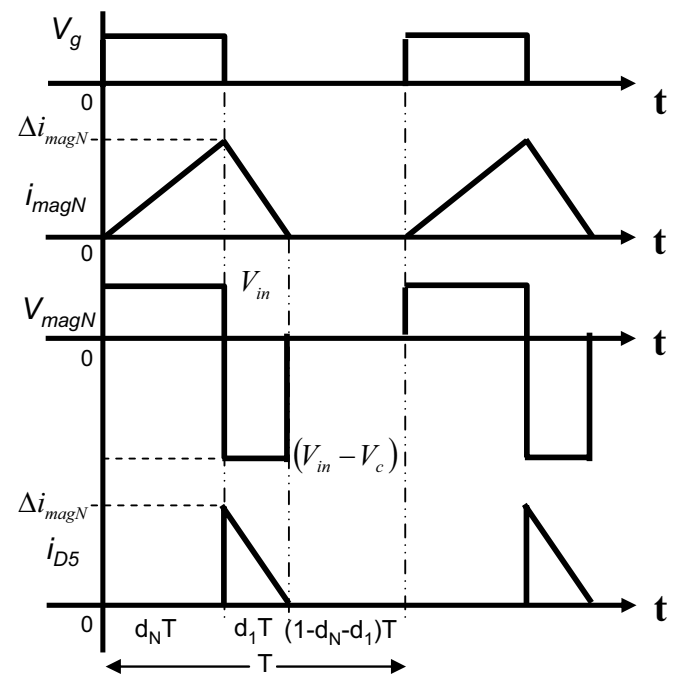

Figure 8. Magnetizing current in normal mode

Magnetizing inductance in transformer (TR) varies in each operation mode too, in the case of normal plus battery charger; it will be determined by equation (6)

$$
L_{\text {magN }}=\mathrm{A}_{\mathrm{L}} \mathrm{N}_{\mathrm{a}}{ }^{2}
$$

Where, $A_{L}$ is the inductance factor from the core; the output voltage in $\mathrm{RCD}$ network $\left(\mathrm{V}_{\mathrm{c}}\right)$ is like a discontinuous conduction mode (DCM) boost converter and is calculated with equation (7)

$$
\mathrm{V}_{\mathrm{CN}}=\frac{\mathrm{V}_{\text {in }}}{2}\left(1+\sqrt{1+\frac{2 d_{N}{ }^{2} R_{c} T}{L_{\text {mag } N}}}\right)
$$

Peak magnetizing current $\left(\Delta i_{\text {magN }}\right)$ and the time to eliminate it $\left(\mathrm{d}_{1}\right)$ every switching period can be obtained form Figure 8 with equations (8) and (9) respectively.

$$
\begin{aligned}
& \Delta i_{\text {magN }}=\frac{V_{\text {in }} d_{N} T}{L_{\text {magN }}} \\
& d_{1}=\frac{\mathrm{V}_{\mathrm{CN}}}{\mathrm{V}_{\text {in }}} \frac{2 L_{\text {magN }}}{R_{C} d_{N} T}
\end{aligned}
$$

\subsection{Back-up mode}

When a fail occurs suddenly in $\mathrm{V}_{\mathrm{AC}}, \mathrm{V}_{\text {in }}$ decrease and $\mathrm{D}_{\mathrm{B}}$ make automatic transition to back-up mode due to the voltage in anode is higher than cathode voltage

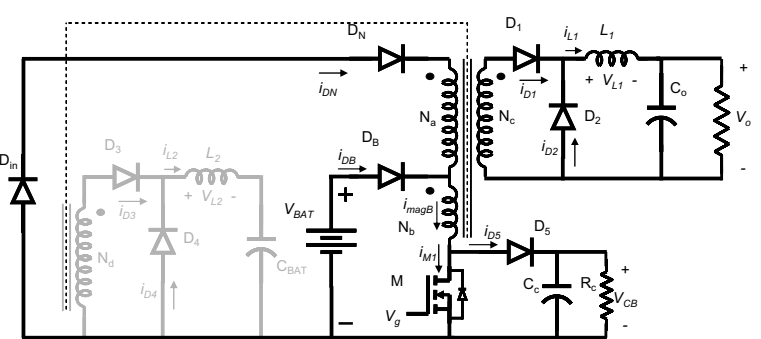

in $\mathrm{D}_{\mathrm{B}}$ allowing fed the load through the battery using the same switch and transformer (Figure 9).

Figure 9. back-up operation mode

In this operation mode the battery charger has to be disconnected from the battery in order to avoid that the energy return to the battery through the transformer causing an efficiency reduction. The battery disconnection from the charger can be made with a simple low frequency interrupter or a simple relay. In addition $V_{\text {in }}$ is substituted by a diode $\left(D_{\text {in }}\right)$ that is formed by full diode rectifier or it can be placed as an additional ultra fast rectifier in parallel with $C_{\text {in }}$ in order to help to manage the magnetizing current $\left(i_{\text {magB } B}\right)$ that results from this operation mode too. When AC main comeback $V_{\text {in }}$ increase and $D_{B}$ is blocked since the cathode voltage is higher than battery voltage $\left(\mathrm{V}_{\mathrm{BAT}}\right)$, achieving normal operation mode again. Equation (10) calculated the output voltage in this operation mode

$$
\mathrm{V}_{\mathrm{o}}=d_{B} \mathrm{~V}_{\text {BAT }} \frac{\mathrm{N}_{\mathrm{c}}}{\mathrm{N}_{\mathrm{b}}}, \quad 0 \leq d_{B} \leq\left(1-d_{2}\right)
$$

Where $d_{B}=$ duty cycle in Back-up mode, $d_{2}=$ time to eliminate magnetizing current, $\mathrm{V}_{\mathrm{BAT}}=\mathrm{dc}$ voltage entrance battery, $\mathrm{N}_{\mathrm{b}}=$ proportional primary winding turns and $\mathrm{N}_{\mathrm{c}}=$ output winding turns. Equation (11) determines the magnetizing inductance in transformer (TR) in this operation mode.

$$
L_{m a g B}=\mathrm{A}_{\mathrm{L}} \mathrm{N}_{\mathrm{b}}^{2}
$$

Equation (12) determines the output voltage $\left(\mathrm{V}_{\mathrm{CB}}\right)$.

$$
\mathrm{V}_{\mathrm{CB}}=\frac{\mathrm{V}_{\mathrm{BAT}}}{2}\left(1+\sqrt{1+\frac{2 d_{B}{ }^{2} R_{c} T}{L_{\operatorname{mag} N}}}\right)
$$

Peak magnetizing current $\left(\Delta i_{\text {magB }}\right)$ and the time to eliminate it $\left(\mathrm{d}_{2}\right)$ are respectively.

$$
\Delta i_{m a g B}=\frac{V_{i n} d_{B} T}{L_{m a g B}}
$$




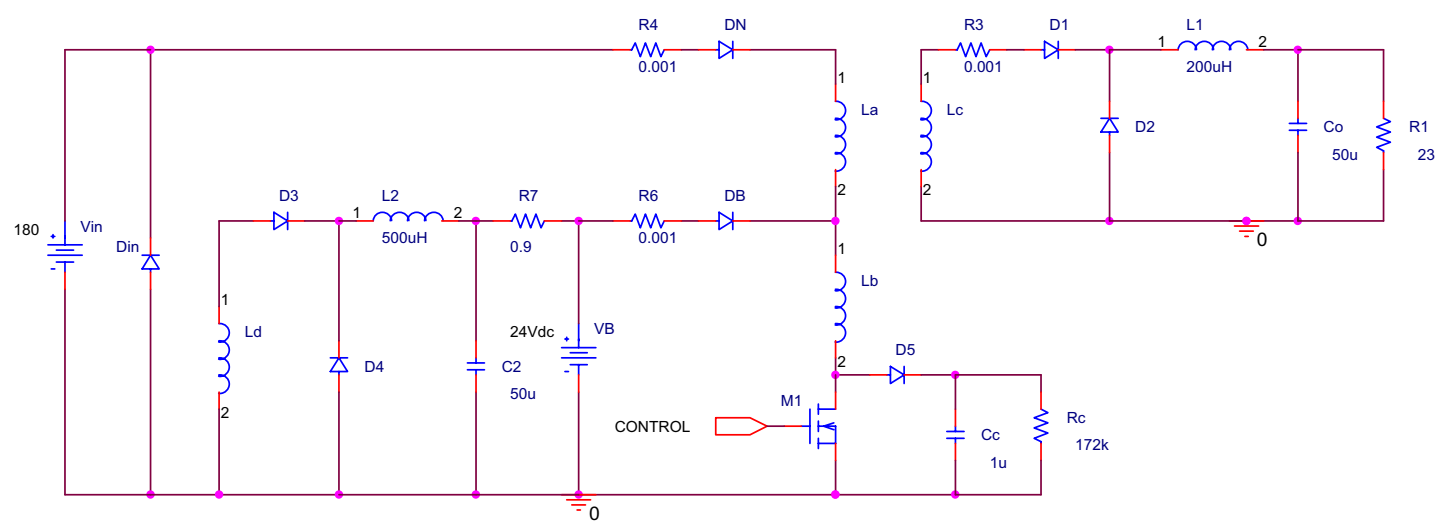

Figure 10. Schematic for simulate Forward-Forward DC-UPS with RCD network.

$$
d_{2}=\frac{\mathrm{V}_{\mathrm{CB}}}{\mathrm{V}_{\mathrm{in}}} \frac{2 L_{m a g N}}{R_{C} d_{B} T}
$$

\subsection{Design considerations}

Design has to take into account the total relation among all the components and semiconductors in the converter as input voltage variation, output power and the possible relation turns in the transformer. Analysis and design of this converter only have to take into account restrictions in construction of the converter because it uses two topologies very known, sharing same transformer, switch and control. The desirable duty cycles in each operation mode, determine the possible turn ration in the transformer.

One important consideration to guarantee the correct operation of the converter in normal operation mode, is to ensure that cathode voltage in $D_{B}$ has to be higher for any rectifier input voltage $\left(\mathrm{V}_{\text {in }}\right)$. In order to accomplish this, equation (15) has to be satisfied.

$$
\mathrm{V}_{\text {in }} \frac{\mathrm{N}_{\mathrm{b}}}{\mathrm{N}_{\mathrm{a}}}>\mathrm{V}_{\mathrm{BAT}}
$$

\section{Simulation results}

In order to verify the operation principle from the converter, a prototype circuit was simulated in PSPICE with the characteristics named in TABLE I. Schematic circuit for simulation is in Figure 10; this circuit simulates the transition from normal operation mode to back-up mode and vice versa back-up to normal mode. Simulation was made in open loop changing the respective duties cycles for each operation mode by a logic circuit, no control loop was simulated. Both entrances were $V_{\text {in }}$ and $V_{\text {BAT. }}$. Results of the converter with suddenly fails in main appear and it is possible to observe that the output voltage does not show significant change in its value. It is observed that the output voltage does not show any transitory when a fail occurs and it made automatic transition from one operation mode to another. Figures 11 and 12 shown waveforms from the converter when a fails occurs and when voltage entrance returns. Dynamic response of the system can be improved adjusting the control loop with the use of the transfer function of the converter.

\section{TABLE I. SPECIFICATIONS FOR SIMULATION}

\begin{tabular}{|l|c|}
\hline Topology & $\begin{array}{c}\text { Forward-Forward with } \\
\text { RCD }\end{array}$ \\
\hline Main AC & $127 \mathrm{~V}_{\text {rms }}$ \\
\hline $\begin{array}{l}\text { DC voltage entrance } \\
\text { from rectifiers }\left(\mathrm{V}_{\text {in }}\right)\end{array}$ & $180 \mathrm{~V}$ \\
\hline Output voltage $\left(\mathrm{V}_{\mathrm{o}}\right)$ & $48 \mathrm{~V}$ \\
\hline Battery voltage $\left(\mathrm{V}_{\mathrm{BAT}}\right)$ & $24 \mathrm{~V}$ \\
\hline Output power $\left(P_{o}\right)$ & $100 \mathrm{~W}$ \\
\hline Switching frequency $\left(f_{s}\right)$ & $100 \mathrm{kHz}$ \\
\hline
\end{tabular}

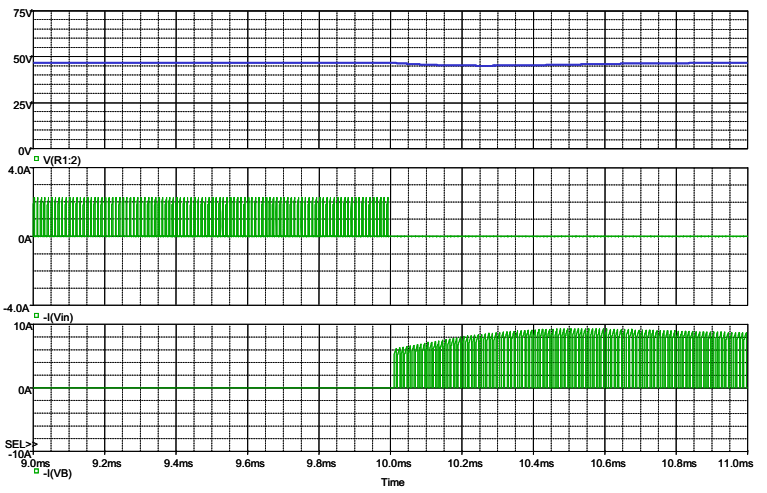

Figure 11. Output voltage (top trace), main current (center trace), and battery current (lower trace). In this case the proposed converter changes from the normal to Back-up 


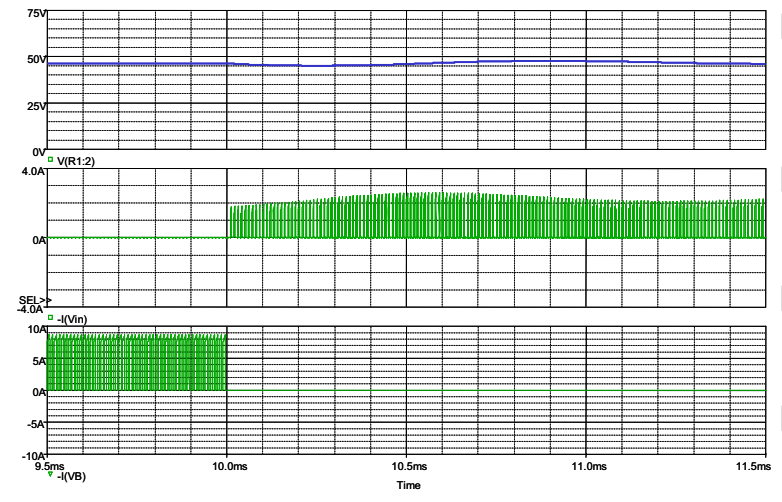

Figure 12. Output voltage (top trace), main current (center trace), and battery current (lower trace). In this case the proposed converter changes from Back-up to normal mode

\section{Conclusions}

A single simple structure of converters has been developed to make automatic transition without fail detects circuit. Preliminary results of the converter shows that is an interesting propose from point of view operation, size, dynamic response and cost because it is a very simple structure based in a Forward or Flyback converter with two outputs. Simulation results show that the converter has a good operation in the transition. The transitions of operation in a one mode operation to another one do not suppose any change in the output voltage, as it were expected.

\section{References}

[1] Solter, W.; "A new international UPS classification by IEC 62040-3”, INTELEC 2002. Page(s):541 - 545

[2] M.S.; Parham, J.D.; Rashid, M.H.; "An overview of uninterruptible power supplies", Racine Power Symposium, 2005. Page(s):159 - 164

[3] Karve, S., "Three of a kind [UPS topologies, IEC standard]" IEE Review, Volume: 46 Issue: 2 , March 2000

[4] Ma, K.-W.; Lee, Y.-S., "A novel uninterruptible DC-DC converter for UPS applications", Industry Applications Society Annual Meeting, 1991
[5] Kwok-Wai Ma; Yim-Shu Lee, "An integrated flyback converter for DC uninterruptible power supply", Applied Power Electronics Conference and Exposition (APEC), 1994

[6] Rodriguez, E.; Arau, J., "A novel DC-UPS with power factor correction in a single structure" Power Electronics Specialists Conference (PESC), 1996

[7] Jain, M.; Daniele, M.; Jain, P., "A high frequency triport topology for low power DC UPS", Power Electronics Specialists Conference(PESC), 1998

[8] Rodriguez, E.; Abud, D.; Arau, J., "A novel single-stage single-phase DC uninterruptible power supply with power-factor correction", IEEE Transactions on Industrial Electronics, Volume: 46 Issue: 6, 1999

[9] Rodriguez, E.; Visairo, H.; Arau, J., "A high efficiency DC-UPS with PFC", Power Electronics Congress (CIEP), 2000

[10] Morrison, R.; Egan, M.G. "A new power-factorcorrected single-transformer UPS design", IEEE Transactions on Industry Applications, Volume: 36 Issue: 1 ,Jan.-Feb. 2000

[11] Fernandez, A.; Sebastian, J.; Martin-Ramos, J.A.; Corral, J.; Ruiz, F., "Multiple output AC/DC converter with an internal DC UPS", Power Electronics Specialists Conference (PESC), 2002

[12] Fuld, B., "A cost-effective DC/DC-converter with integrated UPS-function", Power Electronics and Applications, Fifth European Conference on, 1993

[13] Yuan, X.M.; Lin, W.X., "Integrated uninterruptible DC converter with low input distortion and wide regulation capability", Power Electronics and Variable-Speed Drives, 1994

[14] Cheng, D.K.W.; Leung, F.H., "Design of a switching mode power supply with UPS features", Microelectronics and VLSI (TENCON), 1995

[15] García O., Alou P., Cobos J.A. and Uceda J., "Convertidor $\mathrm{AC} / \mathrm{DC}$ con Back-up Integrado y Transición Automática", Seminario Anual de Automática, Electrónica Industrial e Instrumentación (SAAIE) 2003

[16] C.S. Leu, G.C. Hua, F.C. Lee, "Comparison of Forward Topologies With Various Reset Squemes", Virginia Power Electronics Centre 